\title{
Competition and Collaboration in the Nonprofit Sector: Identifying the Potential for Cognitive Dissonance
}

\section{Authors:}

Cali Curley, PhD

Assistant Professor

Department of Political Science

University of Miami

Jamie Levine Daniel, PhD

Assistant Professor

Paul H. O'Neill School of Public and Environmental Affairs

Indiana University Purdue University Indianapolis

Marlene Walk, PhD

Assistant Professor

Paul H. O'Neill School of Public and Environmental Affairs

Indiana University Purdue University Indianapolis

\section{Nicky Harrison, MPA}

Paul H. O'Neill School of Public and Environmental Affairs

Indiana University Purdue University Indianapolis

Cite as: Curley, C., Levine Daniel, J., Walk, M., \& Harrison, N. (Forthcoming). Competition and Collaboration in the Nonprofit Sector: Identifying the Potential for Cognitive Dissonance. Administration \& Society.

\begin{abstract}
:
Nonprofits compete with collaborators and collaborate with competitors regularly. Collaboration, a long-standing normatively preferred strategy for nonprofits, is utilized as modus operandi without thought to the potential unintended consequences. While competition, long deemed a dirty, word for nonprofits is a necessary but undesirable reality, avoided without consideration to the potential benefits. Nonprofits leaders may not be willing to explicitly acknowledge the use of competition as an operational strategy, which makes room for cognitive dissonance to impact the study of nonprofits. This piece identifies impacts of cognitive dissonance offering direction for future research exploring the interactive nature of competing with collaborators.
\end{abstract}

\section{Keywords: Collaboration, Competition, Nonprofits}

Acknowledgement: We are thankful for the collaboration with Brackets for Good. This study was partly funded by grants from IUPUI's Sports Innovation Institute and Indiana University's Lilly Family School of Philanthropy. 


\section{Competition and Collaboration in the Nonprofit Sector: Identifying the Potential for Cognitive Dissonance}

\section{Introduction}

Nonprofits face increasing scarcity of available resources resulting in the need to become more innovative in service delivery. Collaboration, an operating norm in the nonprofit sector (Gazley, 2010), has been used to decrease burdens on nonprofits through the process of service delivery (Bunger \& Gillespie, 2014; Gazley, 2010), resource sharing and grant seeking (Bunger, 2013). Some view collaboration as normatively good (Gazley, 2010), possessing the potential to overcome a variety of challenges organizations experience (McGuire \& Silvia, 2015). However, collaboration is only one mechanism. Competition is another potential mechanism of innovation (Hill \& Myatt, 2007) and has long been used in the private sector (Goddard, 2015) to drive efficiency. These mechanisms are simultaneously occurring, increasing pressures for nonprofits to collaborate and compete with one another.

Despite scarce resources and an increasing acknowledgement of competition among nonprofits, competition is often faced with scrutiny and viewed as a necessary but undesirable reality by leaders (Sharp, 2018). This may be motivated by the longstanding history that nonprofits have favored collaboration (Lamont, 1991) with its use being commonplace among nonprofits since at least the 1980s (Gazley \& Guo, 2015). Despite the relative avoidance of explicit competition, nonprofits are engaging in different forms of competition with one another (e.g., for clients, grants, donors), a process that creates winners and losers in the pursuit for limited resources (Bunger, 2013). This suggests that while nonprofits are inherently competing, they are also explicitly seeking collaborative opportunities with those same competitors. This 
makes the relationship between competition and collaboration for nonprofits a contradiction that nonprofits leaders must reconcile.

The confluence of collaboration and competition raises a series of questions about how nonprofits actively collaborate with competitors and compete with collaborators. The need to reconcile this confluence of competitors and collaborators who are one and the same may foster cognitive dissonance. This perspective piece posits the presence and implications of cognitive dissonance for nonprofit leaders and future research using support from an explicitly competitive case study.

\section{Cognitive Dissonance}

Tuckman suggested that competition in nonprofit markets is increasing and raised "questions as to the impacts of this rivalry" (1998, p. 175); yet competition in the nonprofit sector remains understudied (Ritchie \& Weinberg, 2000). Despite the evidence that competition matters to nonprofit performance and survival, collaboration is the strategic operating norm (Gazley, 2010) and tied to public perception of nonprofits (Beale, 2014). This can cause nonprofit leaders to preserve collaborative activity as a primary strategy even when utilizing competition would be the more appropriate strategic choice. This tension may cause cognitive dissonance among nonprofit leaders, leading them to disassociate with competition as an organization's operating strategies, despite being actively faced with competition.

The concept of cognitive dissonance, developed by Festinger (1957) and studied largely in the field of social psychology (Jones, 1985), suggests that individuals cannot easily hold on to two potentially competing ideas simultaneously. This results in individuals not truly acknowledging the presence of both ideas because doing so is largely uncomfortable (HarmonJones \& Mills, 2019). This paper uses the term cognitive dissonance to reference the idea that 
holding two potentially conflicting ideas (i.e., collaboration and competition) may result in leaders understating their participation in competitive activities despite being actively engaged in competition. In order to explore how these aspects might influence the activities of nonprofits, we next discuss collaboration and competition as it relates to operational strategies (i.e., internal, external, and programming activities) of nonprofits.

\section{Collaboration \& Competition as Tension for Nonprofits}

There is a long-standing arbitrary assumption that for-profit organizations are cutthroat, rely on efficiency of resources to extract profit, and choose not to collaborate; however, forprofits can collaborate with nonprofits (Austin, 2010), and potentially competitors (Gnyawali \& Park, 2011). Perceptions of the nonprofit sector include a commitment to serve the public good (Kingma, 2003), the rationale that employees are paid less because they feel good about their work (Leete, 2000), and the normative idea that collaboration is necessary to serve the public (Gazley 2010). The public sector has reinforced this distinction by mandating collaboration as a requirement of funding in the nonprofit sector (Guo \& Acar, 2005), particularly in social work (Bailey \& Koney, 1996) and human services (Schmidt \& Kochan, 1977). Despite this, we are seeing increasing amounts of public good accomplished in the private sector (double bottom line of profit and social benefit (e.g., Wilburn \& Wilburn, 2014)) and an increasing acknowledgement of competition within the nonprofit sector (i.e., fundraising, Ashley \& Faulk, 2010).

Collaboration "is the process through which parties who see different aspects of a problem can constructively explore their differences and search for solutions that go beyond their own limited vision of what is possible" (Gray, 1989, p.5). Collaboration can be observed in three capacities, internal among staff and between departments, external with other nonprofits in 
pursuit of obtaining grants and other resources, and through programming by coordinating activities with other organizations to maximize outcomes.

Competition in the nonprofit sector exists in a variety of ways. The most widely discussed is the scarcity of resources and/or clients that nonprofits face, particularly relative to the number of organizations serving a geographic area (Bunger, 2013). Competition can also be observed at the levels of internal, external, and programming, which are described in Table 1. To the extent nonprofit competition has been studied, it has often been from the angle of implicit competition. Despite the limited existing research, competition is often a dirty word (Sharp, 2018) and seen as something to be avoided (Brilliant \& Young, 2004).

\begin{tabular}{|l|l|l|}
\hline Table 1: Different types of competition and collaboration \\
\hline Internal & $\begin{array}{l}\text { Collaboration } \\
\text { achien staff work together to }\end{array}$ & $\begin{array}{l}\text { When staff are benchmarked against } \\
\text { one another to increase performance } \\
\text { and achieve organizational goals }\end{array}$ \\
\hline External & $\begin{array}{l}\text { When organizations work together } \\
\text { to improve their ability to achieve } \\
\text { good in the community }\end{array}$ & $\begin{array}{l}\text { When organizations are forced to seek } \\
\text { limited resources within the community } \\
\text { to achieve a goal }\end{array}$ \\
\hline Programmatic & $\begin{array}{l}\text { When external stakeholders (i.e., } \\
\text { donors or clients) participating in } \\
\text { an organization's activity work } \\
\text { together to achieve a common goal }\end{array}$ & $\begin{array}{l}\text { When external stakeholders (i.e., } \\
\text { donors or clients) participating in an } \\
\text { organization's activity are } \\
\text { benchmarked against one another (solo } \\
\text { or in teams) to achieve a goal }\end{array}$ \\
\hline
\end{tabular}

Given nonprofit social preference for collaboration rather than competition, we suggest that nonprofit leaders are likely to deemphasize competition at a cost to their organization. To illustrate this, we utilize an explicitly competitive fundraising tournament hosted by Brackets for 
Good (BFG) as an example to demonstrate that nonprofit leaders resolve tensions between competition and collaboration through cognitive dissonance.

\section{Case of Explicit Competition:}

BFG, an Indianapolis-based nonprofit organization inspired by the NCAA March Madness (MM) basketball tournament, holds a single elimination bracket-style tournament where nonprofits compete against each other for donations from individuals, whereby those that raise more money than their opponent move on to the next round. Since its inception in 2011, BFG has raised \$9.5 million for nonprofit organizations (Brackets for Good, 2020) and was rated as \#1 "Fundraising Tool to Watch in 2017" (Nonprofit Tech for Good, 2017). The nonprofits are sorted by size and other factors then paired against competitors within a geographic region.

We used a qualitative survey to gauge how nonprofits participating in this explicit direct competition viewed competition as an organizational strategy. We asked nonprofit leaders "Does your organization utilize the concept of competition?" with answer possibilities ranging from "1Not at all" to "5-To a great extent" along three dimensions "Internally (staff, structure), Externally (grants, other nonprofits), Programmatically (events, activities)". This was followed up by an open-ended question ("Please describe the role that competition plays in more detail") prompting the leader to elaborate, which gave them the opportunity to explain their scoring. We then repeated these same questions asking about collaboration.

The responses demonstrate clearly that individuals rated collaboration and its use more highly than competition (see table 2). Many respondents used a normative argument in favor of collaboration, appearing to internalize collaboration as central to their mission. One respondent went as far as to say, "Everything we do is a collaboration", suggesting that their organization was central in working with other nonprofits, but not necessarily accustomed to delivering 
services alone. A representative of a smaller nonprofit stated, "Collaboration is everything for us", suggesting that with limited resources they cannot complete their work without additional support. And lastly, one organization hinted at the tremendous barriers that their work would face in absence of collaboration, stating " $[\mathrm{W}]$ ithout our community partners and without collaboration within our staff, our work would be impossible". One of the organizations spoke to their need to collaborate as "core to who we are," suggesting this type of commitment to collaboration may also be fundamentally part of what the organization does.

\begin{tabular}{|l|c|c|}
\hline \multicolumn{3}{|l|}{ Table 2: Comparison between competition and collaboration } \\
\hline & Competition & Collaboration \\
\hline Avg. Internal Score & 1.47 & 4.35 \\
\hline Avg. External Score & 2.05 & 3.82 \\
\hline Avg. Programmatic Score & 1.94 & 4.29 \\
\hline \# of please describe responses & 12 & 15 \\
\hline Word Count & 333 & 504 \\
\hline Avg Number of Words & 27.75 & 33.6 \\
\hline
\end{tabular}

Given that the literature suggests nonprofits should favor collaboration as a norm, it is unsurprising that nonprofits rated their use of collaboration more highly than competition. However, what is remarkable is that five of the 12 respondents suggested that their organizations did not compete, despite actively engaging in an explicitly competitive fundraising program. This perfectly illustrates that nonprofit leaders may feel the need to engage in cognitive dissonance. The comments about the absence of competition either stated that "there are very 
few organizations that provide services like us" or "we do not have programming competitors" suggesting that they view competition as occurring between specific service delivery elements of the organization. Another respondent explicitly stated that "there really is no competition with the exception of [one of their key programs]," while rating competition a 1. However, one respondent acknowledged that participation in the BFG tournament was "one of the first times" that their organization had ever "really utilize[d] competitive concepts to raise money". Having demonstrated that there is cognitive dissonance, we now illustrate the ways that it manifests in organizational operations (internal, external, and programmatic).

\section{Internal}

Internal collaboration among staff and between departments within an organization is recognized as a management strategy to enable organizations to function more effectively (Naidoo \& Sutherland, 2016; Stone, 2004). Silos within an organization are recognized by most to cause poor performance, and "lead to turf wars, power struggles, and personality conflicts" (Stone, 2004, p. 11) resulting in competition. Through internal collaboration, the goal is to overcome such challenges by promoting trust, communication, cohesiveness and understanding between individuals (Naidoo \& Sutherland, 2016). Internally collaborative organizations are explained to be characterized through "a common identity, centralised integrative configurations, with control practices and incentive systems that reward organisational performance as opposed to individual or business unit performance" (Naidoo \& Sutherland, 2016, p. 77). This focus has multiple potential drawbacks, however, including responsibility shirking and group think (Naidoo \& Sutherland, 2016). Despite this, internal collaboration has also been noted as crucial for the development of a culture that will make the more commonly studied forms of nonprofit collaboration, external and programmatic, work (Bartczak, 2015). 
In our survey of nonprofits leaders one organization rating internal collaboration as a 5 wrote that their organization's "staff work together every day to accomplish tasks" and meet their mission. This sentiment was echoed in many comments that addressed an internal orientation toward collaboration. One nonprofit with a smaller number of employees is "constantly collaborating in the office to accomplish goals", while another speaks to their frontline workers (teachers) "collaborat[ing] quite often across and within their own grade levels" to benefit their participants. The idea of building community within employee teams seemed to be an important component of how they described collaboration with one respondent explicitly stating that "Staff function as a team with an emphasis on 'it's everyone's job' and shared efforts". This is perhaps an orientation toward collaboration but does not necessarily speak to large scale functional collaborations. A respondent suggested that their program engaged in internal collaboration because it allows employees to have input. However, the definitional approach identified above may not explicitly speak to the idea that surface level input is substantive enough to warrant a claim of collaboration.

On the other hand, internal competition "includes the tension over differing values, tension with respect to scarce resources, lack of interfunctional coordination as well as the presence of interfunctional conflict” (Mottner \& Ford, 2007, p.179). Competition among individuals has been found to effectively increase performance (Cagiltay et al., 2015). Internal competition between employees and departments is a management tool used to improve organizational effectiveness (Tjosvold et al., 2006). When relationships between employees of an organization are positive, competitive outcomes are more constructive, with increased effort to achieve, increased innovation, and increased willingness to take on challenging projects contributing to improved performance (Naidoo \& Sutherland, 2016). However, negative 
outcomes are observed as well, including high anxiety, lowered productivity, decreased motivation, increased aggression, decreased communication, diminished creativity, and unethical behavior (Naidoo \& Sutherland, 2016).

Quite telling of its frequency in use, only two respondents elaborated on internal forms of competition, the first stated that their organization has "a staff membership competition" and rated internal competition as two. The second respondent rated internal competition a three and stated that "staff are incentivized to participate in activities such as media post sharing, creative fundraising ideas, community engagement, etc." Both nonprofits speak to the idea that they engage in competition internally, but hesitate to score this highly, likely because they are considering that collaboration plays a much larger role in their overall narrative as an organization.

Managing Cognitive Dissonance: As can be seen these two types of strategies play important roles in improving organizational performance through motivating employee performance. Competitive mechanisms to motivate performance can decrease trust which can harm future collaborative efforts, while collaboration can decrease individual employee performance and lead to less innovative ideas. This suggests that both strategies employed at the right moment in the right ways may be strategically effective. If nonprofit leaders allow cognitive dissonance to detract from the use of competitive strategies internally, they may be less likely to strategically employ competitive strategies leading to the possibility that a nonprofit may fall prey to negative consequences of a collaborative approach. Additionally, if competitive approaches are used without intention or thoughtfulness, they may result in negative consequences from ineffectively used competitive managerial strategies.

\section{External}


External collaboration is characterized as collaboration with other nonprofits in pursuit of access to resources and capital. Such coordination is also becoming more frequently mandated by foundations and grant makers to be selected for funding opportunities (Bunger, 2013). By coordinating organizational resources, knowledge, and capacity, nonprofits seek to increase their legitimacy and influence and, therefore, obtain greater access to additional resources and power (Bunger, 2013). This type of collaboration can be understood as multiple actors, outside of a single organization, with a vested interest in the same problem working together toward a mutually beneficial solution, with a key characteristic being that the solution could not be accomplished by one actor alone (Gazely \& Brudney, 2007). Given the spaces in which many nonprofits function such as poverty, health, and environment, the challenges addressed by programming often require a holistic approach to achieving maximized, sustained outcomes (Wolff et al., 2017). For example, human services nonprofits are collaborating with others who have the same or similar service groups but provide different services to implement a multidimensional approach that addresses the varying interacting needs of individuals, such as physical and mental health (Bunger \& Gillespie, 2014). In such cases, the resource contributions can take the form of tangible assets, knowledge base resources (information, data, technical expertise, etc.), visibility, credibility, political advantage, and trust (McGuire \& Silvia, 2015). This form of collaboration is also recognized to facilitate the identification of and adjustment to the presence of duplicate services among organizations with the same service group to ensure maximized outcomes for the community (Bunger, 2013).

One organization discussed external collaboration from the lens of allowing the community stakeholders opportunities "to express their wishes for programming". While this is a form of participation and engagement, it may not be collaboration. Other respondents described 
their organization's collaboration through the lens of grants by saying "there are partnerships and MOU's that are active and engaging". A larger number of respondents described collaboration through the lens of working "with other nonprofits whenever possible" either to "avoid duplication of services with other local" nonprofits or "to provide much needed services to" participants. One of these organizations was encouraged to "work with other organizations to develop programs and work to break down silos" and "to partner with other like-minded organizations" within their geographic region. Some nonprofits named explicit organizations that they work with while other responses were broader (i.e., "community partners and agencies").

External competition is typically viewed through competition over resources beyond grants and contracts, such as clients or donors (Chetkovich \& Frumkin, 2003), volunteers (Briggs et al., 2010), and grants (Ashley \& Faulk, 2010; Bunger, 2013). The underlying competitive characteristics of grant, contract, and financial processes place nonprofits in the position of 'winning' at the expense of others (Bunger, 2013). Nonprofits are more likely to compete against organizations with similar missions or in a very limited resource pool within a specific geographic area (Irvin, 2010). These forms of resource scarcity force nonprofits to strategize ways to "assert their uniqueness and superiority over rivals" to make the case that they are more deserving of needed resources" (Barman, 2002, p. 1192). This may result in undercutting activities of competitors or differentiating activities to be unique.

Five respondents explicitly referenced external forms of competition, specifically competition when applying for grants. Despite this, external competition is still rated relatively low, receiving a two from a nonprofit that acknowledges their organization "technically compete[s] against other nonprofits for grant money all of the time." This sentiment is shared by other nonprofits rating external competition a two while stating that "the grant process is 
competitive" and while saying that the organization has to stay "competitive with other agencies". The organizations ultimately acknowledge that they "compete for limited funds that are set aside for" specific services; however, they do not necessarily score competition highly.

Managing Cognitive Dissonance: While competition between for-profit organizations is found to increase trust among customers (Huck et al., 2012), it remains unclear as to whether competition in the nonprofit sector fosters trust among donors, clients, and community members. Additionally, it is reasonable to suspect that competition --knowing there are winners and losers - will decrease trust among nonprofits. Competition may increase 'cutthroat' sectoral behavior which could undermine trust further, decreasing collaboration. Competition could enhance mission and activity differentiation for nonprofits, leading to increased efficiencies in service provision for the community. However, this may be viewed by stakeholders as mission drift which occurs when a nonprofit prioritizes activities, often determined by external stakeholders, that differ from its stated mission (Bennett and Savani, 2011), leading to decreased stakeholder and donor support (Jones, 2007). This concept of mission drift may also occur when nonprofits overuse collaborative strategies by prioritizing collaboration with others, losing sight of their original goals and priorities. Similarly, overuse of competitive strategies can decrease an organization's ability to solve problems and serve their clients more meaningfully because they are cut off from resources of other nonprofits. This suggests that nonprofits need to be able to balance both collaborative and competitive strategies understanding the respective implications.

\section{Programmatic}

Programmatic collaboration refers to the idea that the programming of the organization leans on the concept of collaboration. While most research on nonprofit collaboration focuses on internal and external uses, recent discussions call for better understanding coproduction in this 
sector (Gazley \& Cheng, 2020). This call suggests that desired outcomes from nonprofit activities may require closer collaboration between participants, citizens, or service beneficiaries and the nonprofit itself. Examples include what Benjamin and Campbell (2015, p. 989) call codeterminism, which accounts for "how client agency shapes frontline encounters" and, thus, service delivery and outcomes, as well as participatory philanthropy. One example of this might be a nonprofit operating a community garden that relies on volunteers to work together to perform tasks necessary for their programming. Another example is participatory philanthropy (McGinnis, 2012), which actively incorporates community input into grantmaking decisions.

In the survey, nonprofit leaders spoke to how their programming relied on collaborative efforts. Many of these nonprofits spoke to the use of collaboration with other nonprofits to develop programming rather than the use of collaboration with its clientele. This suggests that programmatic collaboration is viewed by nonprofit leaders as external collaboration that creates and establishes a nonprofit program that they run together. The comments spoke to a training program that is "done in collaboration" with other agencies. Some spoke to established relationships that allowed services to be provided more efficiently such as a referral process that was collaborative, with one organization explicitly "rely[ing] on partners to refer us clients, as they rely on us to perform the services they cannot manage internally". Another nonprofit spoke to the specifics of the collaborative effort "partner[ing] with [another organization] every year as we use their facility to conduct our do-good work." This distinction is important because it suggests that collaborative programming rather than programmatic collaboration (co-production) is more common in the field.

Programmatic competition occurs in the form of a game, and the idea behind utilizing competition in programming is to attract participation and volunteers to increase time and money 
donated. Gamification is becoming more common, with the use of interactive experiences to create an engaging environment for individuals to learn about the organization and donate (Nguyen et al., 2012). Frequently built into donor gamification schemes is the public reporting of total donations, such as donor leaderboards, which help to improve status and reputation. Studies that explore these mechanisms find that the publicizing of contributions leads to more altruistic behavior (Hardy \& Van Vugt, 2006). Duffy and Kornienko (2010) confirmed these findings through a laboratory experiment, determining that donations can be increased by strategically taking advantage of the mix of innate competitiveness and natural desire for recognition among peers within most individuals. Other examples of embedding competition into programming include sports-oriented activities and fundraisers such as charitable $5 \mathrm{ks}$, walk-a-thons, or golf tournaments.

There were four comments that acknowledged some degree of competition present in the design of programs. These programs tended to be in the form of "sports competitions ... against other community teams" or the "host[ing] of a $5 \mathrm{k}$ that is competitive" and their respective organizations ranked them as a three and two. The other form of programmatic competition was discussed as "small fundraising events" that encouraged donors or teams to compete to raise money. This activity was scored a three.

Managing Cognitive Dissonance: The levels at which nonprofit leaders speak to collaborative and competitive programming varies. Programmatic collaboration would bring clients and clienteles into the program design process and activities to reach a service mission. However, nonprofit leaders responded by speaking to collaborative programming where nonprofits work together to deliver programming to their clients. Despite engaging in competitive programming (i.e., fundraising tournament) the organizations did not acknowledge 
this in most cases, focusing instead on programs they operate that are competitive in nature (i.e., sports and donor competition). Therefore, even in understanding these concepts nonprofit leaders were determined not to speak to competitive programming in which they actively participated, such as fundraising against other nonprofits, but rather focused on fundraising events that encouraged competition among individual donors. This varied levelling may be the result of cognitive dissonance where nonprofits do not want to admit that they compete with one another. Strategically deploying deliberate sense-giving strategies (Levine Daniel and Eckerd, 2019) can help nonprofits actively manage dissonance across stakeholder groups.

\section{Connecting Collaboration and Competition}

In the introduction of this article, we argued that reconciling collaboration and competition fosters cognitive dissonance among nonprofit leaders. Here we offer two propositions and lay out future research directions. In our case study organizations actively engage in a competitive fundraising tournament, but do not equally or frequently acknowledge that they are, in fact, engaging in competition. In the rare event that a respondent does acknowledge that they "always compete[s] for visitors and grant money", the respondent follows this up by stating that they “don't actively try to compete with others". This suggests that competition may not be well understood as an operational strategy by nonprofit leaders. As demonstrated above, the resolution of cognitive dissonance likely takes precedence over strategic thinking amongst nonprofit leaders. This has implications for understanding nonprofit management, which we elaborate on below.

Proposition 1: Nonprofits engaged in competition will not explicitly acknowledge that they are actively competing. 
We see evidence that cognitive dissonance exists and provides cover to participants to avoid acknowledging that they are, in fact, competing. Based on the literature we know that nonprofits actively compete against other nonprofits for donors, despite this nonprofit leader's statement that they "never really used competitive concepts to raise money". This dissonance needs to be examined to accommodate for potential biases in self-reported measures. Given that self-perception measures appear to inaccurately reflect the amount of competition for nonprofits, we need new innovative methodological strategies based in and tied to social psychology to gauge participation of nonprofits in competitive activities as well as employee/volunteer perceptions of the effectiveness and impacts of those competitive activities.

Cognitive dissonance may lead nonprofits to overstate the benefits of collaboration, particularly since there is a long-standing tradition of embracing collaboration without necessarily knowing its potential drawbacks. Potential consequences of engaging in collaborations include group think (Naidoo \& Sutherland, 2016), stakeholder exclusion (Canavan, 2017), and mission drift (Kwong et al., 2017). The concerns related to groupthink that can grow from internal collaboration (Naidoo \& Sutherland, 2016) may also be applicable to external and programmatic forms of collaboration, but little has been done to explore these effects.

This cognitive dissonance may also mean that organizations underestimate the benefits of competition. Since competition can spur innovation it may be helpful to reframe competition through the study of innovation. Given that competition can spur innovation and may even be considered an innovation itself in the nonprofit sector, we can learn from existing research on innovation. This area of research may be informative in understanding who is more likely to internalize competitive practices. By framing competition as an innovation, scholarship may be 
able to unpack nonprofit willingness to engage in competitive behaviors, the outcomes and impacts from competition in nonprofits, without relying on biased self-reporting.

It may be that resistance to identifying and utilizing competition, despite potential benefits, is also a function of existing risks associated with utilizing competition in a collaborative environment. The risks that may occur from competition include volunteer, staff retention; crowding out donations; threats to organizational identity; resource dependence from non-annual fundraising campaigns; and concerns for trust/reputation in the community. If the perceptions of these risks stem from the normative preference for collaboration, then they may contribute to the existence of cognitive dissonance.

Proposition 2: Nonprofits hesitate to acknowledge that they collaborate with their competitors -or-- compete with their collaborators.

There were two instances in the responses to our open-ended survey that suggested there is some recognition that collaborating with competitors is more common than current research suggests. The organization that rated competition highly (average score 4), suggests that the "challenge is having to compete with large, established organizations... while also working with them in collaborative [ways]". This dynamic explicitly expresses the tension between the dynamics present in the nonprofit world that relies on elements of both competition and collaboration. Another respondent answered a question about collaboration in the following way: "Because we have such a small budget, we try to come up with creative ways to work with others. Unfortunately, the sandbox is not always nice to develop[ing] the needed collaboration." This respondent appears to be speaking to the dynamics that may arise when you are competing with your collaborators. This speaks to the need to understand how competition among collaborators may lead to negative long-term outcomes in favor of potential short-term gains 
(i.e., visitors, donations). It may be easier for nonprofits to acknowledge that they collaborate with their competitors than it would be for them to clearly acknowledge competition with their collaborators.

Given that collaboration occurs among competitors there are likely implications for who gets to collaborate and who gets a voice in collaborations. While this can result in imbalanced power and collaborative failure (Brazil \& Teram, 2009), it can also result in unintentional exclusion. As organizations move to increase the voices of others through collaboration, they may gravitate toward collaborating with those who think or look like them, leading to exclusion. Cognitive dissonance causing the prioritization of competition might lead organizations to mission drift (Kwong et al., 2017), which can disadvantage stakeholders. This may particularly be the case when nonprofits collaborate with external actors and modify services or programming to meet grant requirements (AbouAssi, 2013).

The term co-opetition, emphasized by Walley (2007) to the study of firms that simultaneously held competitive and collaborative relationships, has recently emerged in the study of nonprofits. Co-opetition has been rarely explored in the nonprofit sector (see Kirchner \& Ford 2017 as an exception). Given that the nonprofit sector is normatively collaborative, research on co-opetition must contend with cognitive dissonance among nonprofit leaders.

\section{Conclusion}

There has been a recent push to "re-conceptualiz[e] collaboration and competition as interrelated or interdependent concepts" (Bunger et al., 2014, p. 113). The desire to decrease this conceptual distance is growing (Brown et al., 2017; Kirchner \& Ford 2017); however, few studies explore these concepts in the nonprofit context (McCarthy et al., 2018). This article suggests that practitioners' understanding of collaboration and competition are embedded in the 
perception that collaboration is normatively good, and competition is a reality of circumstances yet not an aspiration. Future research on this topic needs to explore the inclusion of cognitive dissonance, and the implications of competing with collaborators and collaborating with competitors. Emphasizing these streams in future research will greatly enhance our understanding of the benefits and costs associated with competition and collaboration in the nonprofit sector.

\section{References}

AbouAssi, K. (2013). Hands in the pockets of mercurial donors: NGO response to shifting funding priorities. Nonprofit and Voluntary Sector Quarterly, 42(3), 584-602.

Ashley, S., \& Faulk, L. (2010). Nonprofit competition in the grants marketplace: Exploring the relationship between nonprofit financial ratios and grant amount. Nonprofit Management and Leadership, 21(1), 43-57.

Austin, J.E. The collaboration challenge: How nonprofits and businesses succeed through strategic alliances. Vol. 109. John Wiley \& Sons, 2010.

Bailey, D. \& McNally Koney, K. (1996). Interorganizational community-based collaboratives: A strategic response to shape the social work agenda. Social Work, 41(6), 602-611.

Barman, E. A. (2002). Asserting difference: The strategic response of nonprofit organizations to competition. Social Forces, 80(4), 1191-1222.

Bartczak, L. (2015). Building collaboration from the inside out. Washington, DC: Grantmakers for Effective Organizations. https://www.issuelab.org/resources/22852/22852.pdf.

Beale, A.E., "Public Perceptions of the Nonprofit Sector" (2014). University of Montana Conference on Undergraduate Research (UMCUR). 23. Retrieved from https://scholarworks.umt.edu/cgi/viewcontent.cgi?article=1097\&context=umcur 
Benjamin, L.M., \& Campbell, D.C. (2015). Nonprofit performance: Accounting for the agency of clients. Nonprofit and Voluntary Sector Quarterly, 44(5), 988-1006.

Bennett, R., \& Savani, S. (2011). Surviving mission drift: How charities can turn dependence on government contract funding to their own advantage. Nonprofit Management and Leadership, 22(2), 217-231.

Brackets for Good. (2020, March 6). To Brackets For Good's Amazing Fans - [Facebook status update]. Retrieved May 18, 2020 from https://www.facebook.com/215769815107469/posts/3897265116957902/?d=n.

Brazil, M., Teram, E., \& Collaborative Governance Initiative. (2009). Collaboration gone awry: A struggle for power and control over service delivery in the non-profit sector. Syracuse, New York: The Maxwell School, Syracuse University, Program for the Advancement of Research on Conflict and Collaboration E-PARCC.

Briggs, E., Peterson, M., \& Gregory, G. (2010). Toward a better understanding of volunteering for nonprofit organizations: Explaining volunteers' pro-social attitudes. Journal of Macromarketing, 30(1), 61-76.

Brilliant, E., \& Young, D.R. (2004). The Changing Identity of Federated Community Service Organizations. Administration in Social Work, 28(3-4), 23-46.

Brown, J.A., Gianiodis, P., \& Santoro, M.D. (2017). Managing co-opetition for shared stakeholder utility in dynamic environments. California Management Review, 59(4), 114139.

Bunger, A.C. (2013). Administrative coordination in nonprofit human service delivery networks: The role of competition and trust. Nonprofit and Voluntary Sector Quarterly, 42(6), 1155 1175. 
Bunger, A.C., \& Gillespie, D.F. (2014). Coordinating Non-Profit Children's Behavioral Health Services: Clique Composition and Relationships. Health Care Management Review, 39(2), 102.

Bunger, A.C., et al. (2014). Collaboration, competition, and co-opetition: Interorganizational dynamics between private child welfare agencies and child serving sectors. Children and Youth Services Review, 38, 113-122.

Cagiltay, N.E., Ozcelik, E., \& Ozcelik, N.S. (2015). The effect of competition on learning in games. Computers \& Education, 87, 35-41.

Canavan, B. (2017). Tourism stakeholder exclusion and conflict in a small island. Leisure Studies, 36(3), 409-422.

Chetkovich, C., \& Frumkin, P. (2003). Balancing margin and mission: Nonprofit competition in charitable versus fee-based programs. Administration \& Society, 35(5), 564-596.

Duffy, J., \& Kornienko, T. (2010). Does competition affect giving? Journal of Economic Behavior \& Organization, 74(1-2), 82-103.

Festinger, L. (1957). A theory of cognitive dissonance (Vol. 2). Stanford University Press.

Gazley, B. (2010). Why not partner with local government? Nonprofit managerial perceptions of collaborative disadvantage. Nonprofit and Voluntary Sector Quarterly, 39(1), 51-76.

Gazley, B. \& Cheng, Y (2020). Integrating coproduction theory into voluntary sector theories: approaches and implications for Chinese governance. Journal of Chinese Governance 5(1), $28-47$.

Gazley, B., \& Guo, C. (2015). What do we know about nonprofit collaboration? A comprehensive systematic review of the literature. In Academy of Management Proceedings (Vol. 2015, No. 1, p. 15409). 
Goddard, M. (2015). Competition in healthcare: good, bad or ugly?. International Journal of Health Policy and Management, 4(9), 567.

Gray, B. (1989). Collaborating: Finding common ground for multiparty problems. San Francisco, CA: Jossey-Bass. http://www.ncjrs.gov/App/publications/abstract.aspx?ID=122117.

Guo, C., \& Acar, M. (2005). Understanding collaboration among nonprofit organizations: Combining resource dependency, institutional, and network perspectives. Nonprofit and Voluntary Sector Quarterly, 34(3), 340-361.

Gnyawali, D.R., \& Park, B.J.R. (2011). Co-opetition between giants: Collaboration with competitors for technological innovation. Research Policy, 40(5), 650-663.

Hardy, C. L., \& Van Vugt, M. (2006). Nice guys finish first: The competitive altruism hypothesis. Personality and Social Psychology Bulletin, 32(10), 1402-1413.

Harmon-Jones, E., \& Mills, J. (2019). An introduction to cognitive dissonance theory and an overview of current perspectives on the theory.

Hill, R., \& Myatt, A. (2007). Overemphasis on perfectly competitive markets in microeconomics principles textbooks. The Journal of Economic Education, 38(1), 58-76.

Huck, S., Lünser, G.K., \& Tyran, J.R. (2012). Competition fosters trust. Games and Economic Behavior, 76(1), 195-209.

Irvin, R. A. (2010). Collaboration versus competition in the third sector. Handbook of research on nonprofit economics and management, 83-95.

Jones, E.E. (1985). Major developments in social psychology during the past five decades. In G. Lindzey \& E. Aronson (Eds.), The Handbook of Social Psychology (3rd ed., pp. 47-108). New York, NY: Random House 
Jones, M. B. (2007). The multiple sources of mission drift. Nonprofit and Voluntary Sector Quarterly, 36(2), 299-307.

Kingma, B.R. (2003). Public good theories of the nonprofit sector. In: The study of the nonprofit enterprise (pp. 53-65). Springer, Boston, MA.

Kirchner, T.A., \& Ford, J.B. (2017). Coopetition Among Nonprofit Organizations: Strategic and Synergistic Implications of Competition and Cooperation: An Abstract. In Academy of Marketing Science World Marketing Congress (pp. 169-170).

Kwong, C., Tasavori, M., \& Wun-mei Cheung, C. (2017). Bricolage, collaboration and mission drift in social enterprises. Entrepreneurship \& Regional Development, 29(7-8), 609-638.

Lamont, D. (1991). Collaboration Not Competition. The Philanthropist, 10(4). https://thephilanthropist.ca/original-pdfs/Philanthropist-10-4-83.pdf.

Leete, L. (2000). Wage equity and employee motivation in nonprofit and for-profit organizations. Journal of Economic Behavior \& Organization, 43(4), 423-446.

Levine Daniel, J., \& Eckerd, A. (2019). Organizational sensegiving: Indicators and nonprofit signaling. Nonprofit Management and Leadership, 30(2), 213-231.

McCarthy, C., Ford Carleton, P., Krumpholz, E., \& Chow, M.P. (2018). Accelerating Innovation Through Coopetition. Nursing Administration Quarterly, 42(1), 26-34.

McGinnis, J.A. "Participatory philanthropy: An analysis of community inputs impact on grantee selection." PhD diss., Georgia Institute of Technology, 2012.

McGuire, M. \& Silvia, C. (2015). “Managing Effective Collaborations.” In J.L. Perry \& R.K. Christensen (Eds.), Handbook of Public Administration (pg. 293-311). John Wiley \& Sons. 
Mottner, S., \& Ford, J.B. (2008). Internal competition in a nonprofit museum context: development of a scale. International Journal of Nonprofit and Voluntary Sector Marketing, 13(2), 177-190.

Naidoo, S., \& Sutherland, M. (2016). A management dilemma: Positioning employees for internal competition versus internal collaboration. Is coopetition possible?. South African Journal of Business Management, 47(1), 75-87.

Nguyen, T.A., Kodinsky, D., Skelton, W., Kaur, P., Yin, Y., Mathew, A., \& Basapur, S. (2012, June). Interactive philanthropy: an interactive public installation to explore the use of gaming for charity. In Proceedings of the Designing Interactive Systems Conference (pp. $482-485)$

Nonprofit Tech for Good. (2017, February 11). 8 Fundraising Tools to Watch in 2017. Nonprofit Tech for Good, Retrieved from: https://nptechforgood.com/2017/02/11/8-fundraising-toolsto-watch-in-2017/.

Ritchie, R.J., \& Weinberg, C.B. (2000). A typology of nonprofit competition: Insights for social marketers. Social Marketing Quarterly, 6(3), 63-71.

Schmidt, S.M., Kochan, T.A. 1977. Interorganizational relationships: Patterns and motivations. Administrative Science Quarterly 22:220-34

Sharp, Z. (2018). Existential angst and identity rethink: The complexities of competition for the nonprofit. Nonprofit and Voluntary Sector Quarterly, 47(4), 767-788.

Stone, F. (2004). Deconstructing silos and supporting collaboration. Employment Relations Today, 31(1), 11 . 
Tjosvold, D., Johnson, D.W., Johnson, R.T. \& Sun, H. 2006. 'Competitive motives and strategies: Understanding constructive competition', Group Dynamics: Theory, Research and Practice, 10, 87-99.

Tuckman, H.P. (1998). Competition, commercialization, and the evolution of nonprofit organizational structures. Journal of Policy Analysis and Management, 17(2), 175-194.

Walley, K. (2007). Coopetition: an introduction to the subject and an agenda for research. International Studies of Management \& Organization, 37(2), 11-31.

Wilburn, K., \& Wilburn, R. (2014). The double bottom line: Profit and social benefit. Business Horizons, 57(1), 11-20.

Wolff, T., Minkler, M., Wolfe, S.M., Berkowitz, B., Bowen, L., Butterfoss, F.D., \& Lee, K.S. (2017). Collaborating for equity and justice: Moving beyond collective impact. Nonprofit Quarterly, 9, 42-53. 


\begin{tabular}{|c|c|c|}
\hline & Collaboration & Competition \\
\hline Internal & $\begin{array}{l}\text { When staff work together to } \\
\text { achieve organizational goals }\end{array}$ & $\begin{array}{l}\text { When staff are benchmarked against } \\
\text { one another to increase performance } \\
\text { and achieve organizational goals }\end{array}$ \\
\hline External & $\begin{array}{l}\text { When organizations work together } \\
\text { to improve their ability to achieve } \\
\text { good in the community }\end{array}$ & $\begin{array}{l}\text { When organizations are forced to seek } \\
\text { limited resources within the community } \\
\text { to achieve a goal }\end{array}$ \\
\hline Programmatic & $\begin{array}{l}\text { When external stakeholders (i.e., } \\
\text { donors or clients) participating in } \\
\text { an organization's activity work } \\
\text { together to achieve a common goal }\end{array}$ & $\begin{array}{l}\text { When external stakeholders (i.e., } \\
\text { donors or clients) participating in an } \\
\text { organization's activity are } \\
\text { benchmarked against one another (solo } \\
\text { or in teams) to achieve a goal }\end{array}$ \\
\hline
\end{tabular}




\begin{tabular}{|l|c|c|}
\hline \multicolumn{3}{|c|}{ Table 2: Comparison between competition and collaboration } \\
\hline & Competition & Collaboration \\
\hline Avg. Internal Score & 1.47 & 4.35 \\
\hline Avg. External Score & 2.05 & 3.82 \\
\hline Avg. Programmatic Score & 1.94 & 4.29 \\
\hline Word Count & 333 & 504 \\
\hline Avg Number of Words & 27.75 & 33.6 \\
\hline
\end{tabular}

